\title{
Knee and hip kinetics during normal stair climbing
}

\author{
Patrick A. Costigan ${ }^{\mathrm{a}, *}$, Kevin J. Deluzio ${ }^{\mathrm{b}}$, Urs P. Wyss ${ }^{\mathrm{c}}$ \\ ${ }^{a}$ School of Physical and Health Education, Queen's University, Kingston, Ont., Canada K7L 3N6 \\ ${ }^{\mathrm{b}}$ School of Biomedical Engineering, Dalhousie University, Halifax, NS, Canada \\ c Department of Mechanical Engineering, Queen's University, Kingston, Ont., Canada K7L 3N6
}

Accepted 31 October 2001

\begin{abstract}
Understanding joint kinetics during activities of daily living furthers our understanding of the factors involved in joint pathology and the effects of treatment. In this study, we examined hip and knee joint kinetics during stair climbing in 35 young healthy subjects using a subject-specific knee model to estimate bone-on-bone tibiofemoral and patello-femoral joint contact forces. The net knee forces were below one body weight while the peak posterior-anterior contact force was close to one body weight. The peak distal-proximal contact force was on average 3 times body weight and could be as high as 6 times body weight. These contact forces occurred at a high degree of knee flexion where there is a smaller joint contact area resulting in high contact stresses. The peak knee adduction moment was $0.42(0.15) \mathrm{N} \mathrm{m} / \mathrm{kg}$ while the flexion moment was $1.16(0.24) \mathrm{N} \mathrm{m} / \mathrm{kg}$. Similar peak moment values, but different curve profiles, were found for the hip. The hip and knee posterio-anterior shear forces and the knee flexion moment were higher during stair climbing than during level walking. The most striking difference between stair ascent and level walking was that the peak patello-femoral contact force was 8 times higher during stair ascent. These data can be used as baseline measures in pathology studies, as input to theoretical joint models, and as input to mechanical joint simulators. (C) 2002 Elsevier Science B.V. All rights reserved.
\end{abstract}

Keywords: Gait; Stairs; Knee; Hip; Forces; Moments; Patella; Contact forces

\section{Introduction}

While more demanding than level walking, the ability to climb stairs with relative ease is important to one's quality of life. If stair climbing is accompanied by pain and instability then function deteriorates and the perception of disability increases. This may lead to the need for pain medication, therapeutic or, in severe cases, surgical intervention. With an aging population and a concomitant increase in the prevalence of lower limb osteoarthritis (a degenerative joint disease linked to abnormal joint loads) it is imperative that we understand the loads experienced during daily living. Indeed, for patients with early to moderate OA their first complaint is often difficulty with climbing stairs.

In trying to understand the imposed loads during stair climbing several studies have measured the force experienced by healthy subjects. In 1969 Morrison [1]

\footnotetext{
* Corresponding author. Fax: + 1-613-533-2009

E-mail address: 3pac13@post.queensu.ca (P.A. Costigan).
}

presented the joint contact force at the knee for level walking, walking up and down a ramp, and walking up and down stairs. The estimated bone-on-bone reaction force data of two males walking up stairs, the most forceful activity, was 4.25 times body weight. Later, Andriacchi et al. [2] investigated the knee joint moments for 10 men ascending and descending stairs. The flexor moments for stair ascent and descent were much higher than those during level walking.

Researchers have used the more demanding task of stair climbing to describe changes in a patient's functional performance following surgical interventions such as knee replacements [3-6]. For example, Andriacchi et al. [3] compared a group of patients who had between them five different knee prostheses and concluded that both the kinematic and kinetic results of stair climbing could be used to differentiate between constrained and unconstrained prosthesis designs. Clearly, knee dynamics plays an important role in total knee replacement (TKR) performance and evaluation. Since knee replacements are being put in younger, more 
active patients we must look at more stressful activities than level walking. Work on the loads experienced during the endurance sports of cycling, power walking, hiking and jogging acknowledges this [7]. The high contact forces during stair climbing are at higher flexion angles, resulting in higher contact stresses due to lower conformity in the total knee joint replacement. This leads to more abrasion/adhesive and delamination wear.

The purpose of this study was to investigate the knee dynamics in a large group of normal volunteers during stair climbing and estimate the net knee forces and moments. Using a subject specific knee model estimates were made of the joint contact forces and the patellofemoral forces.

\section{Methods}

Thirty-five university students without history or complaint of lower limb pain volunteered for the study. The University's Research Ethics Board approved the study and each subject read and signed an approved letter of informed consent.

During testing each subject wore their preferred comfortable walking shoes and walked at their naturally chosen pace. Motion was recorded using an optoelectric motion tracking system (Northern Digital, Waterloo, Ontario) while a force plate (AMTI, Newton, MA.), embedded in a raised walkway, measured the ground reaction forces. The subject had markers affixed to the lateral aspect of their dominant (test) leg at the greater trochanter, the posterior aspect of the lateral knee condyle, the head of the fibula, and the lateral ankle malleolus. Two additional markers were attached to forward projecting rods strapped securely to the mid thigh and to the upper tibia just below the tubercle. This gave three markers for both the femur (hip, knee, and thigh probe) and the tibia (knee, ankle, and shank probe) that were later used to define local segment coordinate systems. Motion and force data were sampled synchronously at $50 \mathrm{~Hz}$.

Before any motion and force data were collected, each subject had a series of standardized radiographs taken. These were part of the QUESTOR Precision Radiographic (QPR) procedure and included an anterio-posterior view of the hip and the knee as well as a lateral knee view for the test leg only [8,9]. Lead beads taped to the skin at the locations where the motion markers were to be placed were imaged along with the internal bone structure. From the processed radiographs, calibration points, selected bone landmarks and these surface lead beads were digitized using a back-lit $\mathrm{X}$-ray viewing table and a sonic digitizer. Using the calibration points, custom software scaled the coordinate data of the digitized landmarks and lead beads, and computed three-dimensional vectors representing the location of the surface markers, represented by the lead beads, relative to the selected bone landmarks.

Using these vectors, the surface markers were moved to their predetermined bone landmarks. The hip marker was moved to the center of the femoral head in the frontal plane while maintaining its location in the sagittal plane. The knee marker was moved in the frontal plane the center of the sulcus and in the sagittal plane to the center of the posterior aspect of the lateral epicondyle. The tibia marker was moved in both the frontal and sagittal plane to a point between the tibia's intercondylar eminences [10]. All forces and moments were computed about this fixed tibial marker [11].

Additional scaled radiographic measurements helped construct a subject specific knee model [11] used to estimate the forces that generated the joint moments. In this model the sagittal plane moment and the quadriceps' or hamstrings' moment arm are used to estimate the muscle force required to generate the net knee flexion moment. If the external moment is positive then the quadriceps' forces are responsible for the resistive moment; if negative then the hamstrings are responsible. The muscle force is computed by dividing the net moment by the appropriate moment arm and estimating the orientation of the muscle force vector. The quadriceps muscle moment arm is the distance from the knee center to the line of action of the patellar tendon. The hamstrings moment arm is the distance from the knee center to a line projected from the head of the fibula parallel to the longitudinal axis of the femur. The computed muscle force is added to the net knee force based on the direction of pull of either the patellar tendon or the hamstrings. The muscle force is then partitioned into components along the tibal shaft and perpendicular to it and alters the net compressive and anterio-posterior shear forces.

The direction of the muscle forces was determined using measurements from the standing X-rays. The angle of the patellar tendon with respect to the long axis of the tibia represented the angle of pull of the quadricep's force. A line running parallel to the long axis of the femur represented the hamstring's force.

The stairs (rise $=20 \mathrm{~cm}$, run $=30 \mathrm{~cm}$ ) were created by removing a portion of the walkway in front of the force plate so that the force plate became the first step up from the ground. The stepping cycle was defined as the swing phase, toe-off of the test foot from the ground, followed by the stance phase, contact with the force plate until subsequent toe-off from the force plate.

For each subject at least five individual trials were collected. The data were processed as described by Costigan et al. [10] to compute the knee angles using the floating axis technique [12], and forces and moments about the three principal axes for the shank. The 
three principal axes were termed PA (posterior-anterior), LM (lateral-medial), and DP (distal-proximal). The PA axis was roughly the line of progression; LM was an axis running from the lateral to the medial condyle of the femur, while DP represented the long axis of the limb. A positive force was defined as a force directed along an axis while angles and moments were positive using a right-hand rule rotation about the axis.

The forces and moments were computed using the inverse dynamics approach. Segmental inertial properties were estimated using regression equations based on subject specific anthropometrics [13]. In this model the movement at the ankle joint was ignored. The assumption of a fixed ankle has little effect on the computations at the knee since the major forces and moments are experienced during stance when the foot is in contact with the ground. The mass of the foot was not ignored; its mass and the mass of the subject's shoe were included in the shank's mass. The shank's mass moment of inertia was also modified using the principal axis theorem.

In addition to the net forces and moments, the subject-specific knee also produced estimates of the patello-femoral contact force and of the bone-on-bone joint reaction forces [14]. All force and moment data were normalized by body weight and presented as $100 \%$ of the gait cycle. For graphic representation and analysis the average of the five individual trials was used.

\section{Results}

Subject characteristics are presented in Table 1, while group average stair gait cycle parameters are presented in Table 2. The knee joint angle data, computed using the floating axis system, are presented in Fig. 1. The net forces and moments are presented in Figs. 2 and 3. The hip forces and moments are presented in Figs. 4 and 5 while the knee contact forces are presented in Fig. 6 and the single patello-femoral contact force is presented in Fig. 7.

The maximum value of each kinetic curve was extracted for each subject. The averages and standard deviation of these maximums were computed across subjects and by gender. An ANOVA procedure showed that there were no differences between the genders for these maximums except for the lateral-medial (LM) force at the hip. For the females the hip LM force was $1.43 \pm 0.37 \mathrm{~N} / \mathrm{kg}$ while it was lower for the men at $1.10 \pm 0.39 \mathrm{~N} / \mathrm{kg}$.

Level walking data for this subject group have been presented previously [11]. Table 3 compares the curve maxima for level walking and stair climbing.

The knee flexion moment was positive for most of the stance phase. This external moment causes the knee to flex. To maintain rotational equilibrium the knee extensors activate to counter the rotation. Similarly, the adduction moment was also positive, which caused the knee to adduct and is countered by the knee abductors.

The estimated contact forces at the tibia were based on the knee joint net forces and the quadriceps and hamstring muscle force estimated using subject-specific knee models. This model does not account for muscle co-contraction as it assumes that only one muscle group is active at any one time. In addition, the model estimates the muscle force in the sagittal plane therefore the medio-lateral knee joint contact force was identical to the medio-lateral knee joint net force. The results showed that the PA shearing force was close to one body weight while the DP compressive force was on average 3 times body weight and could be as high as 6 times body weight.

\section{Discussion}

\subsection{Knee moment magnitudes}

Several studies have presented peak knee moment values during stair climbing $[2,15,16]$. Tables 4 and 5 presents these previous results.

For the flexion moment, the variation is similar across all studies for which it is available while the maximum moments are quite different from a low of $0.69 \mathrm{~N} \mathrm{~m} / \mathrm{kg}$ to a high of approximately $1.50 \mathrm{~N} \mathrm{~m} / \mathrm{kg}$, almost double. The results from this study agree most closely with those of Kowalk and fall in the middle of the range. Given these differences the flexion moment curve shapes are similar to Refs. $[2,15,16]$ and the current study.

The data from Ref. [15] are this author's estimated average of three subjects while the data from Ref. [17] were for four subjects. The current study had several subjects whose maximum knee moments exceeded 1.5

Table 1

Subject characteristics

\begin{tabular}{lllllll}
\hline Sex & $N$ & Age $(\mathrm{y})$ & Height $(\mathrm{m})$ & Mass $(\mathrm{kg})$ & Limb length $(\mathrm{mm})$ & Tibial length $(\mathrm{mm})$ \\
\hline Males & 15 & 25.6 & 1.8 & 71.7 & 903 & 499 \\
Females & 20 & 23.9 & 1.7 & 60.8 & 856 & 474 \\
Combined & 35 & 24.6 & 1.7 & 65.4 & 876 & 484 \\
\hline
\end{tabular}


Table 2

Stair climbing gait cycle data

\begin{tabular}{lllllll}
\hline & Stride length $(\mathrm{m})$ & Stride time $(\mathrm{s})$ & Stride cadence $(\mathrm{steps} / \mathrm{min})$ & Stride velocity $(\mathrm{m} / \mathrm{s})$ & Swing/stance ratio & Stance time $(\mathrm{s})$ \\
\hline Average & 0.65 & 1.49 & 0.44 & 40.78 & 0.32 & 0.47 \\
SD & 0.03 & 0.16 & 0.05 & 4.27 & 0.03 & 0.06 \\
\hline
\end{tabular}

$\mathrm{N} \mathrm{m} / \mathrm{kg}$ suggesting that the average of only a small number of subjects may give misleading population averages, but that individual data would be very important for clinical decision making.

Only a few authors have presented knee adduction moment magnitudes during stair climbing. Table 5 summarizes them and presents them with the current study for comparison. The negative value reported in Ref. [1] reflects a different naming convention but still refers to a positive external adductor moment, as do the other studies.

The larger adduction moment values presented in Ref. [15] may be explained by the assumptions of relative surface marker placement to internal bone landmarks. In the frontal plane the knee moment is a function of both the external load and the distance of the joint center from the ground reaction force vector. While the mass acceleration of the shank is a factor that must be considered, it contributes only a small percentage of the total dynamic load, especially in the stance phase. The current study used a set of orthogonal radiographs to measure the relationship between the skin markers and the bone landmarks. Kowalk et al. [15] used the GAITLAB package [17] which estimates the relationship between the skin markers and the bone landmarks. Small errors in locating the joint center in the frontal plane will affect the estimated length of the moment arm and have a large impact on the computed moment [10].

\subsection{Knee moment profiles}

Within the first $20 \%$ of the stance phase the external knee flexion moment increased sharply to $1.0 \mathrm{~N} \mathrm{~m} / \mathrm{kg}$ and then dropped to zero through $20-40 \%$ of stance. This positive moment must be resisted by the action of the knee extensors. During this same interval the hip flexion moment dropped to $-0.75 \mathrm{~N} \mathrm{~m} / \mathrm{kg}$ and then back to zero in an almost mirror image of the knee's moment profile. The negative moment at the hip must be countered by the action of the hip extensors. So, during the first phase of stance both the knee extensors and hip extensors were increasingly active which agrees with the EMG findings from several authors [18-20].

In comparison to level walking the magnitude of the adduction and rotational moments were similar. The flexion moment was twice as large with a total range (minimum to maximum) of $1.3 \mathrm{~N} \mathrm{~m} / \mathrm{kg}$ compared with the range of $0.6 \mathrm{~N} \mathrm{~m} / \mathrm{kg}$ for level walking. When examining the flexion angle at which these moments occurred during level walking where the largest moments occur during stance, the knee was not flexed more than $20^{\circ}$. On the other hand, during stair climbing the largest moment occurred when the knee was flexed to about $60^{\circ}$.

\subsection{Knee net forces}

The maximum values for the net knee forces were not different between level walking and stair ascent and the curve profiles for these two activities were similar in all three force directions. As with the knee moment profiles, the relationship between the loads and the knee angles was quite different. Again, all the loading during level walking occurred while in the stance phase with knee flexion ranges of less than $20^{\circ}$. During stair ascent the maximum load again occurred at about $60^{\circ}$ of knee flexion, where the contact area in TKR is smaller, leading to higher stress and potentially more wear at the articulating surface.

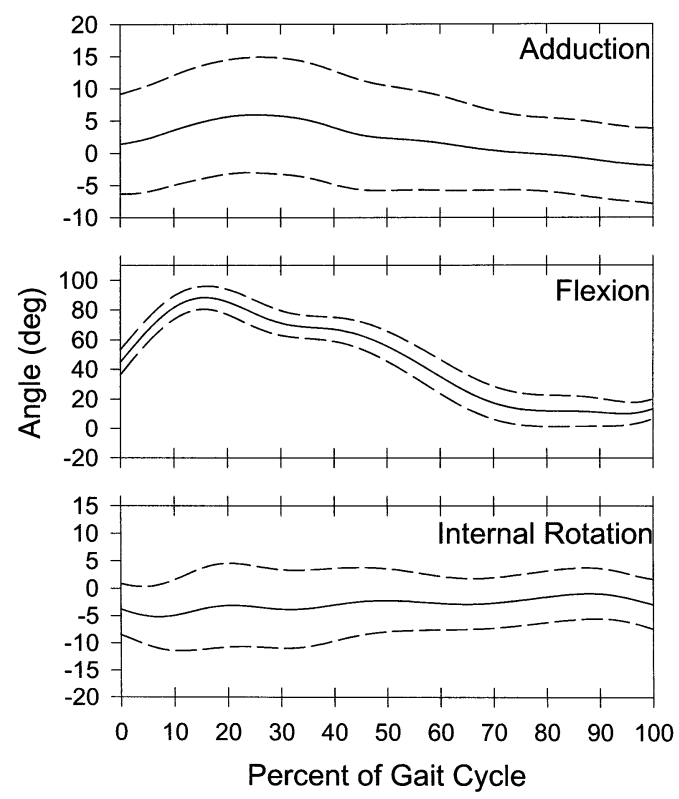

Fig. 1. Knee angles for young normal subjects during stair ascent $(N=35)$. The knee angle is positive in the direction indicated by the graph label. The solid line represents the group mean while the dashed line represents \pm one standard deviation. 

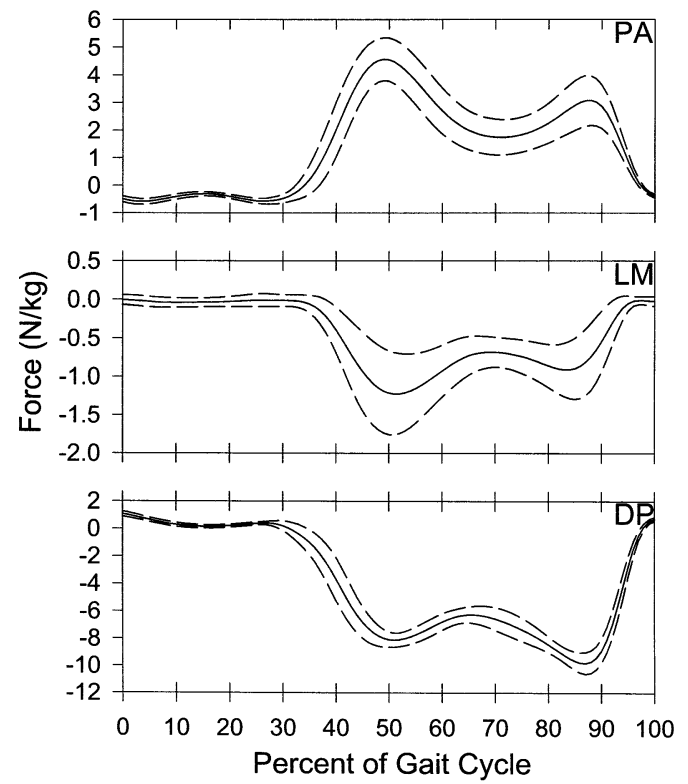

Fig. 2. Knee forces for young normal subjects during stair ascent $(N=35)$. A positive force is in the direction of the specified axis. PA: Posterior to anterior; LM: Lateral to medial; and DP: Distal to proximal. The solid line represents the group mean while the dashed line represents \pm one standard deviation.

\subsection{Contact and patellar forces}

The net joint reaction forces discussed above did not include the force of muscle contraction. The net forces result only from the ground reaction forces and limb accelerations. If the muscle forces, computed using the

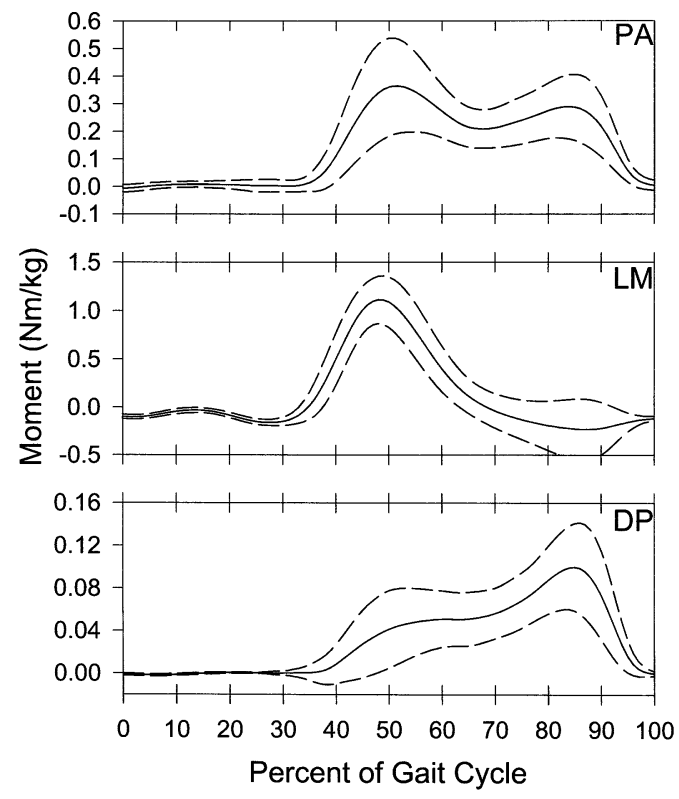

Fig. 3. Knee moments for young normal subjects during stair ascent $(N=35)$. A positive moment is about the specified axis using the right-hand rule. PA: Posterior to anterior; LM: Lateral to medial; and DP: Distal to proximal. The solid line represents the group mean while the dashed line represents \pm one standard deviation.

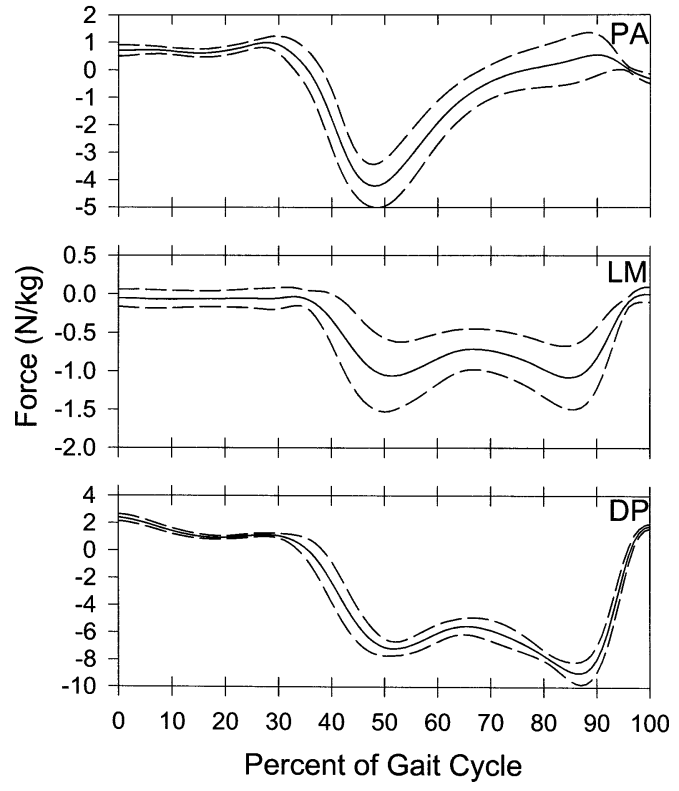

Fig. 4. Hip forces for young normal subjects during stair ascent $(N=35)$. A positive force is in the direction of the specified axis. PA: Posterior to anterior; LM: Lateral to medial; and DP: Distal to proximal. The solid line represents the group mean while the dashed line represents \pm one standard deviation.

subject specific knee model, are added the contact forces can be estimated.

With the addition of the muscle force the forward shear force during stair ascent changed dramatically. Its magnitude doubled and was negative early in stance. The PA force becomes negative as the knee moment becomes positive. The positive moment, tending to flex

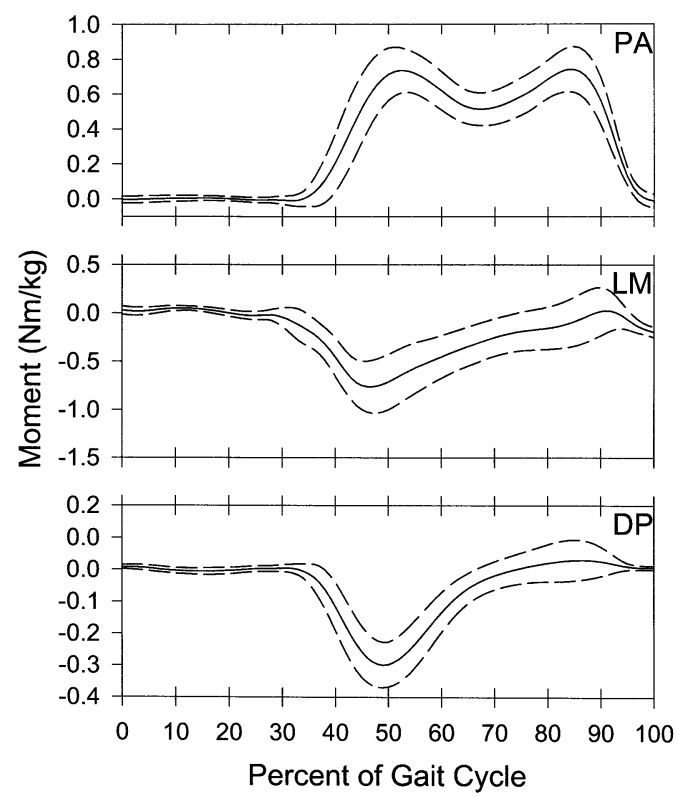

Fig. 5. Hip moments for young normal subjects during stair ascent $(N=35)$. A positive moment is about the specified axis using the right-hand rule. PA: Posterior to anterior; LM: Lateral to medial; and DP: Distal to proximal. The solid line represents the group mean while the dashed line represents \pm one standard deviation. 


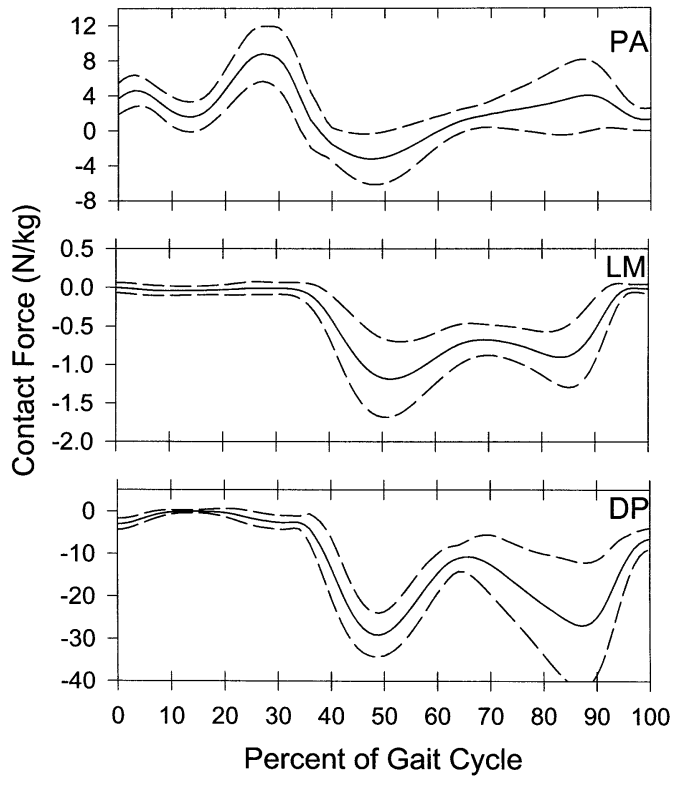

Fig. 6. Estimated knee contact forces for young normal subjects during stair ascent $(N=35)$. A positive force is in the direction of the specified axis. PA: Posterior to anterior; LM: Lateral to medial; and DP: Distal to proximal. The solid line represents the group mean while the dashed line represents \pm one standard deviation.

the knee is countered by the activation of the quadriceps. The quadriceps is attached to the tibia tubercle via the patellar tendon. An increase in the pull of the quadriceps increases the tension in the patellar tendon and tends to pull the tibia forward and upward.

The vertical component of this force also increased the axial force along the tibial shaft. The maximum force was no longer equal to 1 times body weight but rose to an average of 3 times body weight and as high as $4-5$ times body weight in some subjects. These values are comparable to those presented in Ref. [21]. In Morrison's work there were two distinct force peaks, one after foot strike and one before toe-off. The same peaks were present in these data with the second peak being slightly smaller and more variable than the first.

The patellar force results from the activation of the quadriceps muscle group. In the current model, if there is a net quadriceps moment then there will be some force in both the quadriceps tendon and the patellar tendon

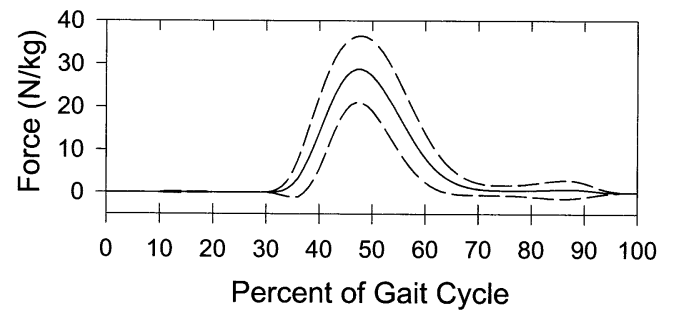

Fig. 7. Estimated patellar contact forces for young normal subjects during stair ascent $(N=35)$. The solid line represents the group mean while the dashed line represents \pm one standard deviation.
Table 3

Comparison of stair climbing and level walking curve maxima

\begin{tabular}{|c|c|c|c|c|}
\hline \multirow[t]{2}{*}{ Curve parameter } & \multicolumn{2}{|c|}{ Stair climbing } & \multicolumn{2}{|c|}{ Level walking } \\
\hline & Avg. & SD & Avg. & SD \\
\hline PA knee force $(\mathrm{N} / \mathrm{kg})$ & 4.73 & 0.70 & 3.22 & 0.50 \\
\hline LM knee force $(\mathrm{N} / \mathrm{kg})$ & 1.32 & 0.48 & 1.45 & 0.53 \\
\hline DP knee force $(\mathrm{N} / \mathrm{kg})$ & 9.87 & 0.79 & 9.99 & 0.53 \\
\hline $\begin{array}{l}\text { PA knee moment } \\
\qquad(\mathrm{N} \mathrm{m} / \mathrm{kg})\end{array}$ & 0.42 & 0.15 & 0.49 & 0.19 \\
\hline $\begin{array}{l}\text { LM knee moment } \\
\qquad(\mathrm{N} \mathrm{m} / \mathrm{kg})\end{array}$ & 1.16 & 0.24 & 0.54 & 0.14 \\
\hline $\begin{array}{l}\text { DP knee moment } \\
(\mathrm{N} \mathrm{m} / \mathrm{kg})\end{array}$ & 0.10 & 0.04 & 0.13 & 0.04 \\
\hline PA hip force (N/kg) & 4.38 & 0.74 & 2.78 & 0.63 \\
\hline LM hip force $(\mathrm{N} / \mathrm{kg})$ & 1.29 & 0.40 & 1.43 & 0.38 \\
\hline DP hip force (N/kg) & 9.05 & 0.83 & 8.89 & 0.40 \\
\hline PA hip moment $(\mathrm{N} \mathrm{m} / \mathrm{kg})$ & 0.80 & 0.12 & 0.95 & 0.14 \\
\hline $\begin{array}{l}\text { LM hip moment } \\
\qquad(\mathrm{N} \mathrm{m} / \mathrm{kg})\end{array}$ & 0.80 & 0.24 & 1.13 & 0.30 \\
\hline DP hip moment $(\mathrm{N} \mathrm{m} / \mathrm{kg})$ & 0.31 & 0.07 & 0.15 & 0.06 \\
\hline PA contact force $(\mathrm{N} / \mathrm{kg})$ & 11.68 & 4.09 & 4.98 & 1.60 \\
\hline LM contact force $(\mathrm{N} / \mathrm{kg})$ & 1.27 & 0.45 & 1.43 & 0.53 \\
\hline DP contact force $(\mathrm{N} / \mathrm{kg})$ & 33.87 & 10.95 & 36.36 & 10.54 \\
\hline Patellar force $(\mathrm{N} / \mathrm{kg})$ & 30.19 & 7.86 & 3.41 & 2.41 \\
\hline
\end{tabular}

resulting in a patellar reaction force. If there is a net hamstrings moment then there is no quadriceps or patellar tendon force and therefore no patellar reaction force. The results showed that the patellar force was on average 3 times body weight at $45 \%$ of the gait cycle when the knee flexion angle was just over $60^{\circ}$. Perry et al. [22] using an instrumented cadaver estimated patellar forces of 2.1 times body weight at a knee angle of $60^{\circ}$ for standing. Cadaver work by Singerman et al. [23] established that at $60^{\circ}$ of knee flexion a flexion moment of 5.7 $\mathrm{N}$ m resulted in a patello-femoral contact force of $160 \mathrm{~N}$. Combining these data with data from the current study $\left(60^{\circ}\right.$ of knee flexion: at $47 \%$ of the gait cycle; knee moment: $1.1 \mathrm{~N} \mathrm{~m} / \mathrm{kg}$; subject mass: $65 \mathrm{~kg}$ ) would predict patello-femoral joint contact forces of $30.9 \mathrm{~N} / \mathrm{kg}$, which is very close to the $28.7 \mathrm{~N} / \mathrm{kg}$ average presented here.

Table 4

Comparison of maximal knee flexion moments $(\mathrm{N} \mathrm{m} / \mathrm{kg})$

\begin{tabular}{lcc}
\hline Researchers & Average & SD \\
\hline Andriacchi et al. [2] & 0.76 & 0.24 \\
Andriacchi et al. [3] & 0.69 & 0.29 \\
McFadyen and Winter [15] & $\sim 1.50$ & N/A \\
Marovich et al. [17] & 1.46 & 0.25 \\
Kowalk et al. [16] & 0.92 & 0.23 \\
Costigan et al. [10] & 1.16 & 0.23 \\
\hline
\end{tabular}

\footnotetext{
${ }^{a}$ The results were reported in ( $\%$ body weight/height); values from the current study were used to convert to $\mathrm{N} \mathrm{m} / \mathrm{kg}$.

${ }^{\mathrm{b}}$ Estimated from a graph of three subjects.

${ }^{\mathrm{c}}$ The results were reported as normalized by body weight and height; values from the current study were used to convert to $\mathrm{N} \mathrm{m} / \mathrm{kg}$.
} 
Table 5

Comparison of maximal knee adduction moments $(\mathrm{N} \mathrm{m} / \mathrm{kg})$

\begin{tabular}{lrc}
\hline Researchers & Average & SD \\
\hline Andriacchi et al. [12] & -0.46 & 0.23 \\
Kowalk et al. [16] & 0.62 & 0.11 \\
Costigan et al. [10] & 0.42 & 0.14 \\
\hline
\end{tabular}

Work by Berchuck et al. [5] on the gait adaptations of patients with deficient anterior cruciate ligaments found a "quadriceps-avoidance" gait during level walking, but not during stair ascent or descent and suggested that resistance to the forward shearing forces was provided by other structures. The magnitude of the patello-femoral contact forces measured in this study is much larger during stair ascent than during level walking and is directed backward through the patella. This large force vector likely reduces the stress on the anterior cruciate allowing the patient to perform stair climbing as would a healthy individual. On the other hand, for the patient with early osteoarthritis, the increased force on the patella during stair ascent may well be the cause for the pain experienced.

The angle, force, and moment patterns at knee along with their variations have been presented for a group of 35 young persons. When compared to level walking, stair climbing produces greater forces and moments. These curves can be used to help establish normative profiles for stair climbing which can then be used to evaluate changes to gait function with surgical interventions and therapy procedures, and to assess the differences between the normal profile and the profiles of those who have difficulty with stair gait.

\section{References}

[1] Morrison JB. Function of the knee joint in various activities. J Biomed Eng 1969:573-80.

[2] Andriacchi TP, Andersson GBJ, Fermier RW, Stern D, Galante JO. A study of lower-limb mechanics during stair-climbing. J Bone Joint Surg 1980;62A:749-57.

[3] Andriacchi TP, Galante JO, Fermier RW. The influence of total knee-replacement design on walking and stair-climbing. J Bone Joint Surg 1982;64A:1328-35.

[4] Dorr LD, Ochsner JL, Gronley J, Perry J. Functional comparison of posterior cruciate retained versus cruciate-sacrificed total knee arthroplasty. Clin Orthop 1988;236:36-43.
[5] Kelman GJ, Biden EN, Wyatt MP, Ritter MA, Colwell CW. Gait laboratory analysis of a posterior cruciate sparing total knee arthroplasty in stair ascent and descent. Clin Orthop 1989;248:21-6.

[6] Berchuck M, Andriacchi TP, Bach BR, Reider B. Gait adaptations by patients who have a deficient anterior cruciate ligament. J Bone Joint Surg 1990;72A:871-7.

[7] Kuster MS, Spalinger E, Blanksby BA, Gachter A. Endurance sports after total knee replacement: a biomechanical investigation. Med Sci Sports Exerc 2000;32:721-4.

[8] Wevers HW, Siu D, Cooke TDV. A quantitative method of assessing malalignment and joint space loss of the human knee. J Biomed Eng 1982;4:319-24.

[9] Cooke DTV, Sorbie C, Scudmore RA, Bryant JT, Siu D, Fisher B. A quantitative approach to radiography of the lower limb: principles and applications. J Bone Joint Surg 1991;73B:715-20.

[10] Costigan PA, Wyss UP, Deluzio KJ, Li J. Semiautomatic threedimensional knee motion assessment system. Med Biol Eng Comput 1992;30:343-50.

[11] Li J. Queen's University, $\mathrm{PhD}$ thesis, 1992.

[12] Grood ES, Suntay WJ. A joint coordinates system for the description of three dimensional motions: application to the knee. J Biomed Eng 1983;105:136-44.

[13] Clauser EC, McConville JT, Young JW. Weight volume and centre of mass of segments of the human body. AMRL Technical Report 69-70, Wright Patterson Air Force Base, Ohio (Ntis No. AD-710-622); 1969.

[14] Li J, Wyss UP, Costigan PA, Deluzio KJ. An integrated procedure to assess knee-joint kinematics and kinetics during gait using an optoelectric system and standardized X-rays. J Biomed Eng 1993;15:392-400.

[15] McFadyen B, Winter DA. An integrated biomechanical analysis of normal stair ascent and descent. J Biomech 1988;24:733-44.

[16] Kowalk DL, Duncan JA, Vaughan CL. Abduction-adduction moments at the knee during stair ascent and descent. J Biomech 1996;29:383-8.

[17] Marovich GD, Riley PO, Krebs DE, Mann RW, Hodge WA. Biomechanical analysis of knee motion upon stair ascent and descent. ASB 13th Vermont Aug; 1989. p. 116-7.

[18] Vaughan CL. Dynamics of human gait. 2nd ed. Human kinetics, Champaign, IL; 1992.

[19] Joseph J, Watson R. Telemetering electromyography of muscles used in walking up and down stairs. J Bone Joint Surg 1967;49B:774-80.

[20] Panjabi MM, Goel VK. Errors in kinematic parameters of a planar joint: guidelines for optimal experimental design. J Biomech 1982;15(7):537-44.

[21] Lyons K, Perry J, Gronley JK, Barnes L, Antonelli D. Timing and relative intensity of hip extensors and abductor muscle action during level and stair ambulation. Phys Ther 1983;63:1597-605.

[22] Perry J, Antonelli D, Ford W. Analysis of knee-joint forces during flexed-knee stance. J Bone Joint Surg 1975;57A:961-7.

[23] Singerman R, Berilla J, Kotzar G, Daly J, Davy DT. A six-degree-of-freedom transducer for in vitro measurement of patellofemoral contact forces. J Biomech 1993;27:233-8. 